\title{
Implementación de un Dron Anticolisiones Capaz de Seguir una Trayectoria Preestablecida para la Elaboración de un Mapa de la Tasa de Ocupación Vegetal en una Zona
}

\section{Implementation Of An Anti-Collision Drone Capable Of Following A Pre- Established Trajectory For The Elaboration Of A Map Of The Plant \\ Occupation Rate In An Area}

Fabricio Javier Santacruz Sulca ${ }^{1}$, Fausto Ramiro Cabrera Aguayo ${ }^{2}$, Wilson Jhonatan Olmedo Carrillo ${ }^{3}$, Jhonny Paul Tacuri Auquilla ${ }^{4}$.

\begin{abstract}
. DOI: https://doi.org/10.33262/cienciadigital.v3i3.3.827

An unmanned flight system was implemented, which is able to detect obstacles and avoid collisions. The drone is capable of taking images for further processing, it shows the percentage and size of vegetation in through the plots into a GUI in Matlab software..
\end{abstract}

Keywords: Drone, Anti-collisions, Precision Farming.

\footnotetext{
${ }^{1}$ Escuela Superior Politécnica de Chimborazo, Facultad de Informática y Electrónica. Riobamba, Ecuador. fabricio.santacruz@espoch.edu.ec

${ }^{2}$ Escuela Superior Politécnica de Chimborazo, Facultad de Informática y Electrónica. Riobamba, Ecuador. fausto.cabrera@espoch.edu.ec

${ }^{3}$ Escuela Superior Politécnica de Chimborazo, Facultad de Informática y Electrónica. Riobamba, Ecuador. wilson.olmedo@espoch.edu.ec

${ }^{4}$ Escuela Superior Politécnica de Chimborazo, Facultad de Informática y Electrónica. Riobamba, Ecuador. jhony.tacuri@espoch.edu.ec
} 


\section{Resumen.}

Se implemento un sistema de vuelo no tripulado, el cual es capaz de detectar obstáculos y evitar colisiones. El drone es capaz de tomar imágenes para su posterior procesamiento con lo cual se logra obtener el porcentaje y tamaño de ocupación vegetal en las parcelas, mostradas gráficamente en una GUI en el programa de Matlab

Palabras claves: Dron, Anti-colisiones, Agricultura de precisión.

\section{Introducción.}

En las últimas dos décadas la agricultura de precisión ha ido mejorando sus métodos del tratamiento de la información en los cultivos y con la incorporación de drones para la recolección de información (Murugan, Garg, Ahmed, \& Singh, 2018), se han obtenido resultados aceptables con los cuales se puede estimar las condiciones en las que los terrenos se encuentran. Las imágenes aeras de los cultivos nos permiten distinguir entre un suelo cultivado y no cultivado, pero aun no se puede clasificar los diferentes tipos de labranza. El uso de drones para las técnicas de visión computarizada nos permite monitorizar las parcelas sin importar su dimensión y de ese modo tomar los correctivos necesarios (Tripicchio, Satler, Dabisias, Ruffaldi, \& Avizzano, 2015).

Muchos drones se desplazan por trayectorias predeterminadas con la ayuda de sensores colocados en los puntos a los cuales deberá llegar y mientras ejecuta la misión, debe ir adquiriendo imágenes en el trayecto (Moribe, Okada, Kobayashl, \& Katayama, 2018). Al usar esta técnica se debe considerar la reducción del consumo de batería para prolongar la vida útil de los nodos de sensores. La inclusión de los drones en este campo ha tenido una buena aceptación en países de primer mundo, no obstante, su acogida en el resto de la población no ha sido la esperada. Estos problemas se dan debido a la falta de conocimiento del potencial que se puede llegar a tener con estos equipos para mejorar el tratamiento de los cultivos (Yallappa, Veerangouda, Maski, Palled, \& Bheemanna, 2017).

El ambiente en el que operan los drones es mayormente conocido y procurando que se encuentre alejado de obstáculos (Devos, Ebeid, \& Manoonpong, 2018), sin embargo, un desafío importante para el drone es evadir obstáculos en entornos complejos. Para estos fines los dornes son controlados por un piloto a través de un FPV o vuelan de forma autónoma 
mediante auto-posición utilizando un GPS, pero debido a limitaciones del GPS en aéreas cerradas se puede estimar la auto ubicación mediante el uso de sensores o el procesamiento de imágenes (Morita, Kinjo, \& Sato, 2018). Los drones se están volviendo ampliamente disponibles, participando en tareas que implican un acceso difícil para los seres humanos. En términos de navegación, los drones son mas versátiles que los vehículos terrestres (Wang, Yadav, \& Balakrishnan, 2007), ya que pueden despegar y aterrizar verticalmente además de mantenerse suspendido en el aire y detener su movimiento bruscamente.

La segmentación de imágenes es encontrar grupos de píxeles que” van juntos” (Jain, Ray, \& Bhavsar, 2015), entonces se ha propuesto la intervención de un operador humano en la segmentación de imágenes de modo que sea interactiva. Los filtros de imágenes son de importancia en el momento de reconocer determinados pixeles para su reconstrucción y manipulación (Jian, Bin, Hua, Lei, \& Li, 2013). En el procesamiento de imágenes un desafío que se presenta es lidiar con las variaciones de intensidad originadas por la iluminación entre ellas (Rivaz, Karimaghaloo, \& Collins, 2014), por lo tanto, es necesario estimar un margen de tolerancia para poder estimar la similitud de los pixeles en cada una de las imágenes procesadas.

\section{Metodología.}

La implementación del drone anticolisiones capaz de seguir una trayectoria para obtener imágenes de una zona cumple con los objetivos planteados en el proyecto de investigación, es por ello por lo que, para su desarrollo se usa los métodos de observación y experimentación, es decir estrategias basadas en la experiencia, la practica y el análisis de los hechos, con el fin de llegar a la solución eficaz del problema planteado.

El problema se divide en varias etapas muy bien estructuradas, es decir pequeños problemas mas sencillos, esto con la finalidad de lograr la completa resolución del problema principal de manera optima y teniendo en cuenta que cada etapa lleva su tiempo de construcción.

\section{Elección del kit de desarrollo}

Para elegir el kit adecuado se tomaron en consideración las carteristas que cada uno de los dos kits mas accesibles poseen y finalmente optando por el kit de Intel Aero RTF. En la 
Figura 1 se muestra el ensamble final del drone junto con el sistema de prevención de colisión.

Tabla 1. Características de los elementos que poseen los kits SLAMdrunk e Intel Aero

\begin{tabular}{lll}
\hline \multicolumn{1}{c}{ Parrot SLAMdunk } & \multicolumn{1}{c}{ Intel Aero Ready to Fly } \\
\hline Procesador & NVIDIA Tegra K1 & Intel Atom x7-z8750 \\
RAM / Memoria & 2 GB DDR3 / 16 GB & 4 GB DDR3 / 32 GB \\
Sensores & $\begin{array}{l}\text { IMU, Magnetómetro, } \\
\text { barómetro, ultrasónico }\end{array}$ & IMU, Magnetómetro, Barómetro \\
Cámaras & Resolución 1500 x1500 a 60 FPS & $\begin{array}{l}\text { RGB 8MP y VGA monocromático, RealSense } \\
\text { R200 }\end{array}$ \\
Controlador de vuelo & ------------------------ & Controlador Intel Aero, SMT 32 \\
Sistema Operativo & Ubuntu, ROS & Linux Yocto, soporte para Ubuntu/ ROS \\
Aplicación & $\begin{array}{l}\text { Sistema para navegación } \\
\text { Autónoma, evasión de } \\
\text { obstáculos y mapeo 3D, } \\
\text { aplicable a drones y otra clase } \\
\text { de robots. }\end{array}$ & $\begin{array}{l}\text { Desarrollo y prueba de aplicaciones para } \\
\text { drones, soporte de tecnología Intel } \\
\text { RealSense para interacción con el usuario, } \\
\text { detección de objetos y mapeo 3D }\end{array}$ \\
\hline
\end{tabular}

Tabla 2. Comparación entre SLAMdrunk e Intel Aero

\begin{tabular}{lcc}
\hline & Parrot SLAMdunk & Intel Aero RTF \\
\hline Mayor capacidad de procesamiento & $\mathrm{NO}$ & $\mathrm{SI}$ \\
Soporte para varios sensores & $\mathrm{SI}$ & $\mathrm{SI}$ \\
Mayor soporte para cámaras & $\mathrm{NO}$ & $\mathrm{SI}$ \\
$\begin{array}{l}\text { Sistema Operativo de código abierto } \\
\text { Controlador de vuelo incluido }\end{array}$ & $\mathrm{SI}$ & $\mathrm{SI}$ \\
$\begin{array}{l}\text { Versatilidad para desarrollar sistemas de navegación } \\
\text { autónoma }\end{array}$ & $\mathrm{NO}$ & $\mathrm{NO}$ \\
$\begin{array}{l}\text { Partes y componentes necesarios para montaje de un } \\
\text { UAV }\end{array}$ & $\mathrm{SI}$ & $\mathrm{NO}$ \\
\hline
\end{tabular}


Figura 1. Ensamblaje final del drone

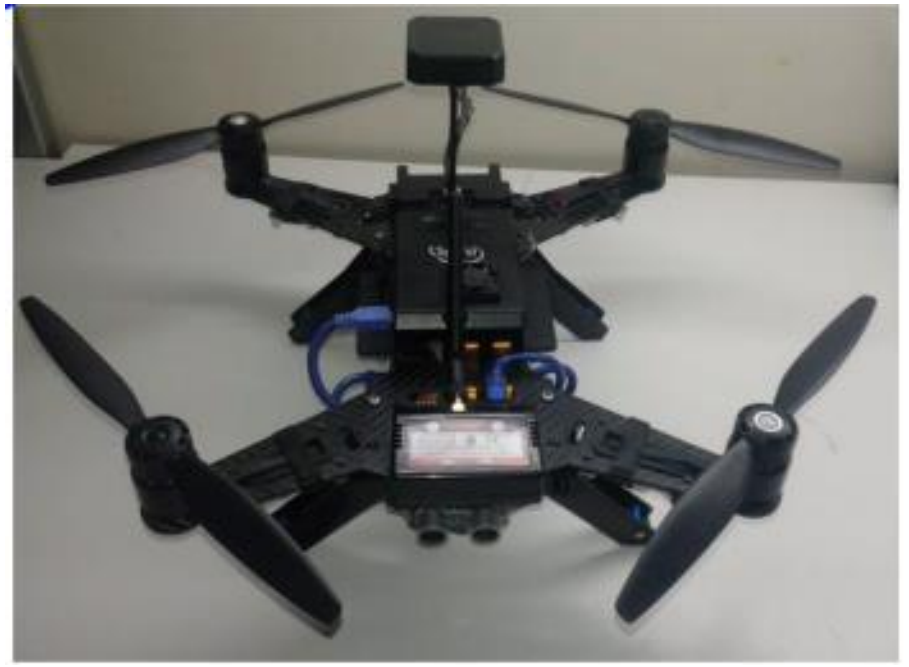

Elaborado por: Grupo de Investigación.

\section{Procesamiento de Imágenes}

Para la adquisición de las imágenes de las misiones realizadas y su debido procesamiento, se utilizó la cámara Xioma YI Lite debido a su precio y Angulo de captura de $35 \mathrm{~mm}$ el cual nos permite obtener imágenes de 120 grados.

\section{Algoritmo del reconocimiento panorámico}

Entrada: $n$ imágenes desordenadas.

1. Extraer las características SIFT de todas las n imágenes.

2. Encontrar $\mathrm{k}$ vecinos mas cercanos para cada característica usando un árbol k-d

3. Para cada imagen:

a) Seleccionar $m$ imágenes de coincidencia de candidatos.

b) Encontrar coincidencias de características geométricas utilizando RANSAC para resolver la homografía entre pares de imágenes.

c) Verificar que las imágenes coincidan con el modelo probabilístico.

4. Buscar componentes conectados de coincidencias de imágenes.

5. Para cada componente conectado: 
a) Realizar el ajuste del paquete para resolver la rotación y la distancia focal.

b) Renderizar panorámicas usando cultivadas.

Salida: imagen panorámica.

Con la ayuda de Matlab se procede a implementar el algoritmo y con la ayuda de la librería VLFEAT se pudo conseguir resultados favorables debido a que posee librerías como: FISHER, VECTOR, VLAD, SIFT, MSER, entre otras:

\section{Componentes Principales En El Reconocimiento De Imágenes}

Los procesos principales son el algoritmo de Stitching y el algoritmo de Segmentación, entonces se debe proceder de la siguiente forma:

- La primera parte que se realiza es la carga de imágenes las cuales están separadas en carpetas para luego reducir su tamaño con un factor de escala de 0.45.

- Se debe encontrar los pares de imágenes, detectando características entre I(n) y I(n1), estimando la transformada geométrica de I(n) a I(n-1) y calculando la misma. Para ello se convierte la imagen a escala de grises y con el uso del algoritmo SURF encontramos los puntos característicos de la imagen, luego estimamos la trasformada geométrica entre los puntos antes encontrados y finalmente calculamos la trasformada para crear la imagen panorámica.

- Utilizando la segmentación de color, realizamos la técnica de similitud y mediante un margen de tolerancia ingresado, obtenemos el color seleccionado de la imagen como se puede ver en la figura 2.

Con los valores de cada pixel se puede determinar el porcentaje y tamaño aproximado de cada imagen panorámica únicamente se debe tomar en cuenta todos los aspectos que se presentan en las ecuaciones (1) y (2). $E=\frac{H+h v}{f}$ 
Figura 2. Pruebas de similitud en las imágenes.

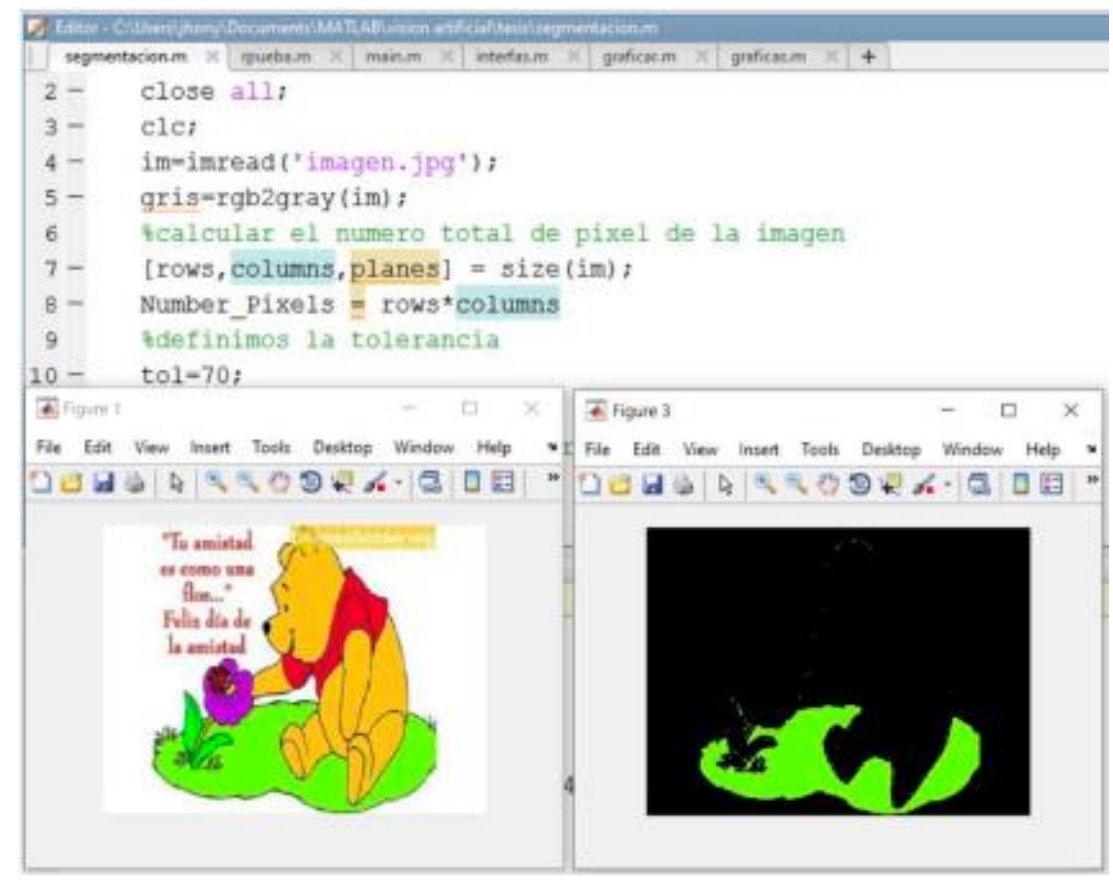

Elaborado por: Grupo de Investigación.

$$
\text { vegetacion }=\frac{n}{E} * r * f c
$$

Donde:

- E: Escala de la imagen.

- H: Altura desnivel del terreno.

- hv: Altura de vuelo del dron sobre el terreno.

- f: Distancia focal de la cámara.

- n: Numero de pixeles segmentados.

- r: Resolución de la imagen en pixeles por pulgada.

- fc: Factor de conversión de pulgada a m.

- vegetación: Área de ocupación vegetal. 
Para un mejor análisis de resultados e interpretación de este valor se procedió a dividir a toda la zona en sectores mas pequeños como se muestra en la figura 3, que nos permitirán conocer de mejor manera en que parte se encuentra la mayor y menor concentración de vegetación.

\section{Sistema Anticolisiones Basado En Un Sensor Ultrasónico}

Para realizar una misión con las debidas precauciones es necesario contar con un sistema que permita detectar obstáculos, evaluarlos y evitarlos para poder proteger el drone ante posibles amenazas en espacios cerrados. Al utilizar un sensor ultrasónico situado en la parte frontal del fuselaje del drone y con una distancia de detecciondeobjetosenalmenos4metros, se pudo hacer una intervención en la señal del transmisor del dispositivo, desactivando los motores y generando un aterrizaje de emergencia. La acción de parar progresivamente las revoluciones en los motores se efectuó alterando el valor del potenciómetro que controla el movimiento vertical del drone, la señal a cargo de permitir que la tarea se lleve a cabo fue enviada y recibida por antenas NFR14101 junto con arduinos nano, que controlan la comunicación entre las antenas.

Figura 3. Interfaz del programa de reconstrucción, subdivisión y determinación de la población vegetal

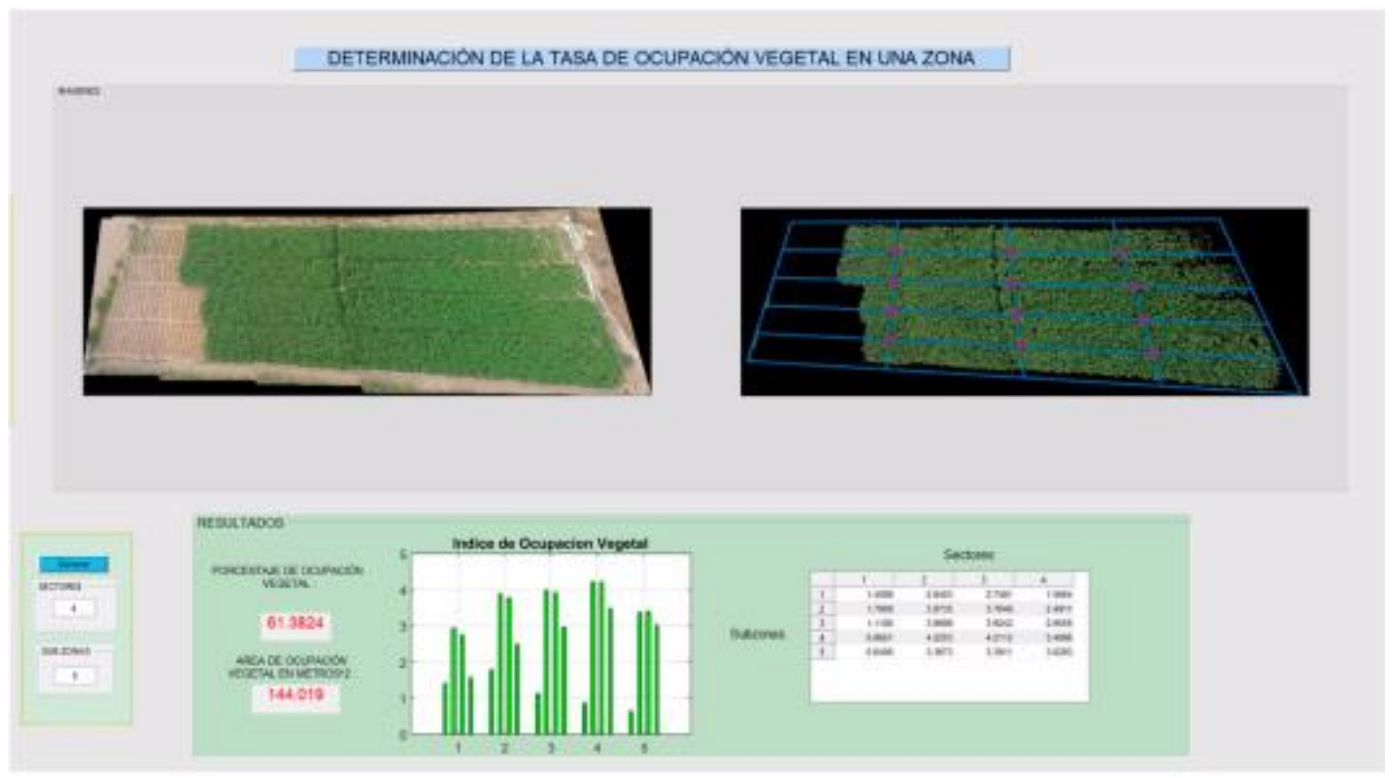

Elaborado por: Grupo de Investigación. 
Figura 4. D.F. del transmisor del sistema de paro de emergencia

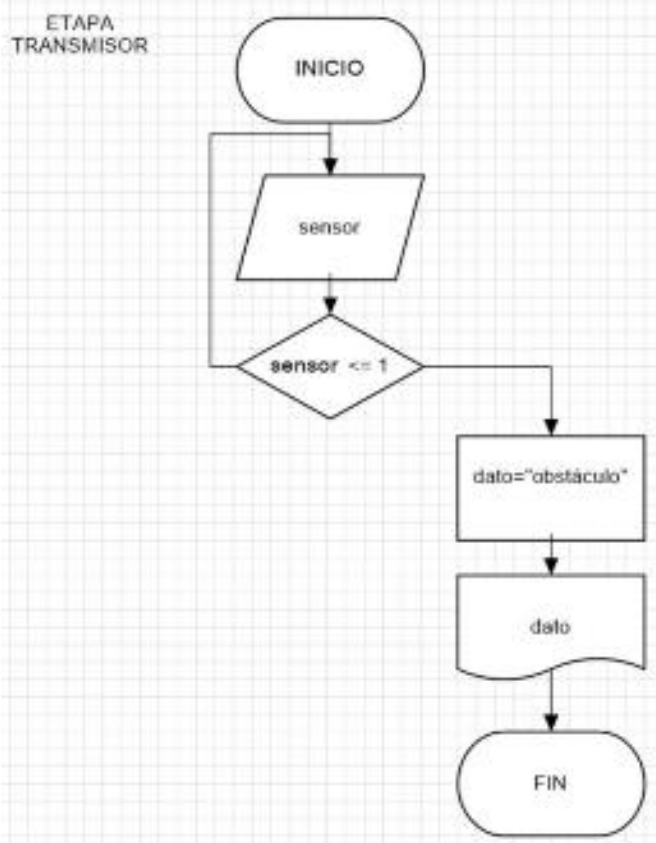

Elaborado por: Grupo de Investigación.

Las figuras (3) y (4) muestran el principio de funcionamiento del transmisor y receptor del sistema anticolisiones

Figura 5. Receptor del sistema de paro de emergencia

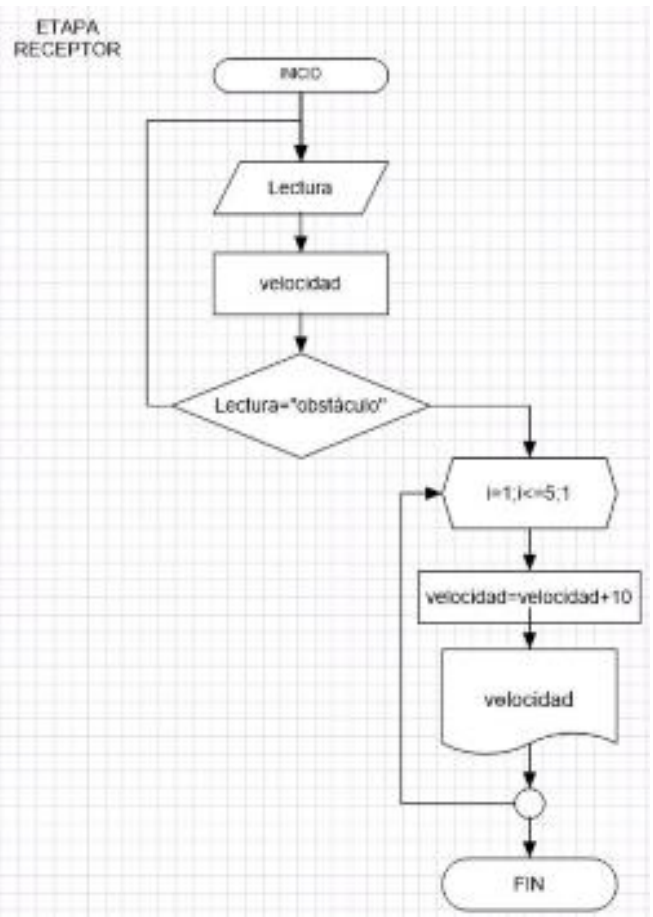

Elaborado por: Grupo de Investigación. 


\section{Planeación de la misión mediante una estación de control en tierra.}

Para realizar la planificación de la misión se procedió a utilizar el programa QGround Control el cual tiene soporte para PX4. Se debe establecer una conexión con el drone con la finalidad de poder monitorear de manera remota el estado actual del drone en vuelo. Planear la misión en este software se basa en determinar los puntos que debe recorrer el drone con la ayuda conjunta de un GPS integrado en el mismo.

\section{Ventana de planeación de misión:}

Main Toolbar: Ubicada en la parte superior de la pantalla de la figura 6. Muestra los datos principales de la misión, como la distancia a recorrer, tiempo de la misión, altitud del drone, entre otros.

Figura 6. Ventana de herramientas de configuración de una misión.

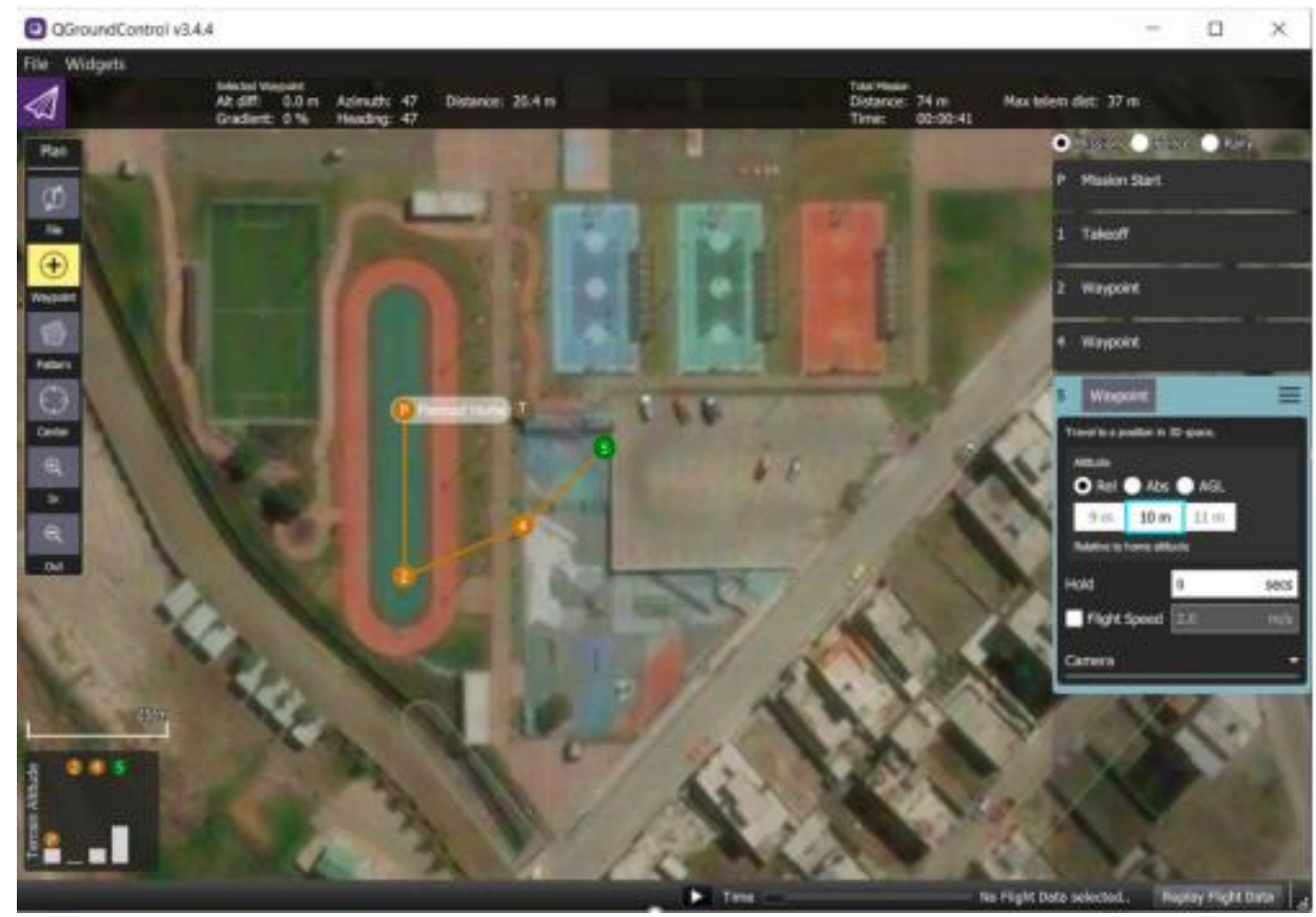

Elaborado por: Grupo de Investigación.

Plan Tools: Son las herramientas que se usan para crear la trayectoria de la misión, definiendo los puntos de recorrido "Waypoints" y el punto de finalización de la ruta.

Command Editor: Ubicado en la parte derecha de la ventana. En esta herramienta se puede modificar los parámetros de vuelo que va a recorrer el drone en cada uno de los puntos definidos en la herramienta de planeación, como es la velocidad, altura y tiempo de espera. 
Una vez definidos los puntos de trayectoria y procurando un desplazamiento en línea recta junto con los parámetros de vuelo como velocidad de desplazamiento y altura, se procede a cargar la misión en el drone. Para recorrer la misión establecida, el transmisor debe tener un canal configurado en modo "Mission" para que de tal modo se pueda mandar a ejecutar la misma.

\section{Resultados}

\section{Análisis de la reconstrucción de imágenes.}

Para la captura de las imágenes se utiliza la cámara deportiva Xiaomi, situado 90 grados con respecto al fuselaje del dron con un time lapse de $3 \mathrm{~s}$, logrando obtener imágenes con un solapamiento aproximado de $60 \%$ entre imágenes. Para este ejemplo se capturo una secuencia de 5 imágenes, las cuales son almacenadas en la memoria microSD de la cámara para posteriormente cargarlas a la computadora de manera manual una vez terminada la misión de vuelo.

Figura 7. Secuencia de imágenes obtenidas en la misión.
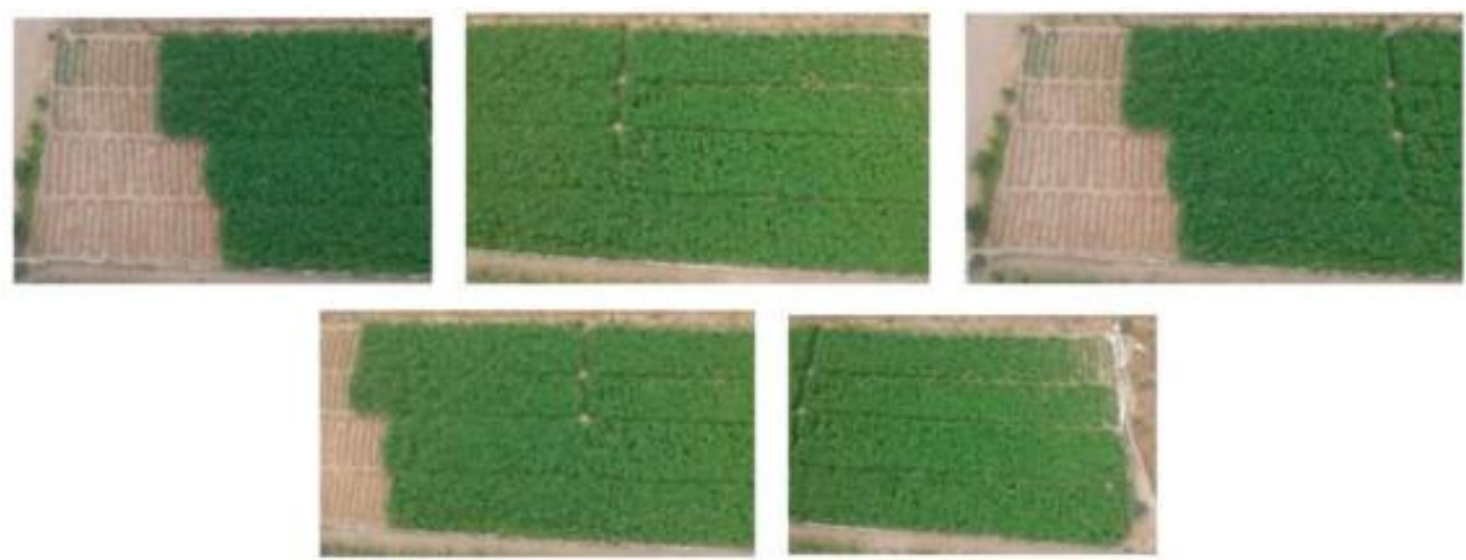

Elaborado por: Grupo de Investigación.

Cabe mencionar que el programa soporta cambios en parámetros de rotación, escala y el orden de las imágenes. En la prueba realizada se estima la robustez del algoritmo, procediendo a cambiar el orden de la secuencia inicial de imágenes, obteniendo un resultado similar al original, debido a que el algoritmo trata de buscar la imagen central dentro de la secuencia y en base a esta, se procede a la unión con las demás imágenes. También se procedió a variar el tamaño y la orientación de una de las imágenes, se utilizaron imágenes 
de 3968x2976 pixeles y una imagen de 1786x1340 pixeles, con la cual probamos que el tamaño y la orientación de la imagen no afecta al resultado final.

Figura 8. Imagen reconstruida.

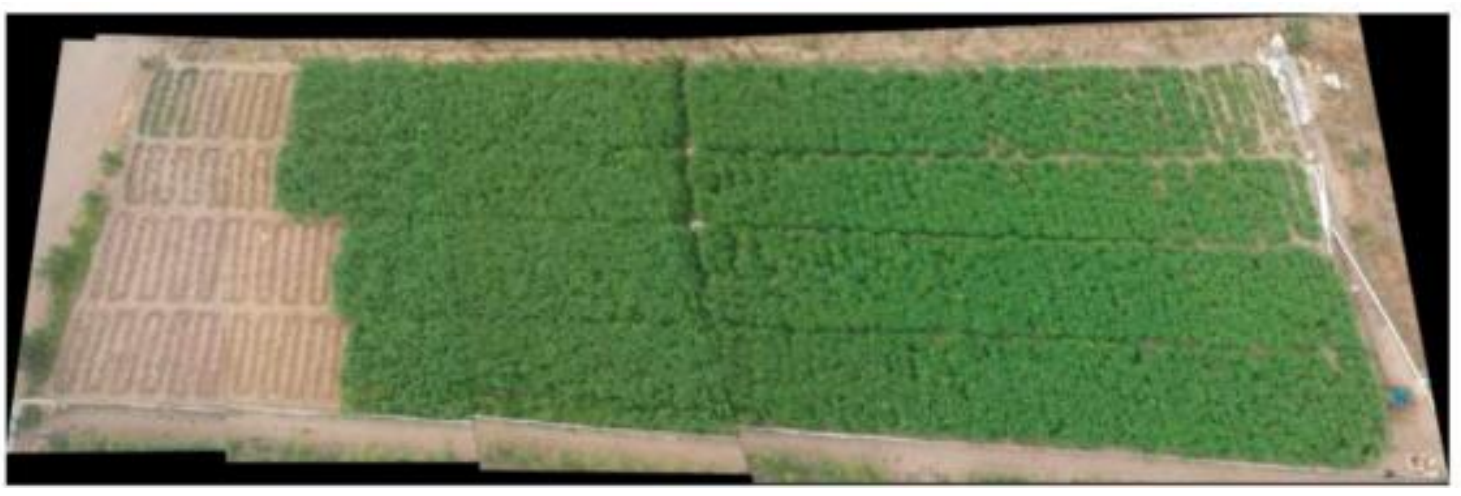

Elaborado por: Grupo de Investigación.

En la tabla 3 se realizo una comparación entre las diferentes pruebas realizadas, obteniendo los siguientes resultados.

Tabla 3. Comparación de resultados de la reconstrucción de imágenes, variando parámetros.

\begin{tabular}{|c|c|c|c|c|c|}
\hline $\begin{array}{l}\text { CARPETA } \\
\text { (MISION) }\end{array}$ & $\begin{array}{l}\text { NÚMERO } \\
\text { IMAGENES }\end{array}$ & $\begin{array}{c}\text { PARAMETRO } \\
\text { VARIADO }\end{array}$ & $\begin{array}{c}\text { TIEMPO } \\
\text { DE SALIDA } \\
\text { (SEGUNDOS) }\end{array}$ & $\begin{array}{l}\text { RESOLUCION } \\
\text { DE SALIDA } \\
\text { (PIXELES) }\end{array}$ & RESULTADO \\
\hline 1 & 4 & NINGUNO & 00:09.69 & $2897 \times 1508$ & Aceptable \\
\hline 7 & 4 & DESORDEN & 00:10.94 & $2578 \times 1582$ & Aceptable \\
\hline 8 & 4 & TAMAÑO & $00: 08.60$ & $2964 \times 1585$ & Aceptable \\
\hline 9 & 4 & ORIENTACION & 00:09.29 & $2567 \times 1459$ & Aceptable \\
\hline
\end{tabular}

\section{Sistema anticolisiones.}

De acuerdo con las pruebas establecidas con el drone se ha establecido el rango máximo en la detección de objetos en el sensor ultrasónico con una distancia de detección aproximada de $4 \mathrm{~m}$ debido a la velocidad con la que los motores disminuyen sus revoluciones cuando se lleva a efecto el bloqueo del acelerador en el transmisor del drone se puede definir la distancia de separación con el obstáculo en la que el dron efectuó el aterrizaje. Se puede estimar la 
distancia de descenso que describe el dron pudiendo así conocer la altura máxima en la que el sistema será funcional, como se muestra en la figura 9.

Figura 9. Valores de separación del drone al momento de generar el paro de emergencia.

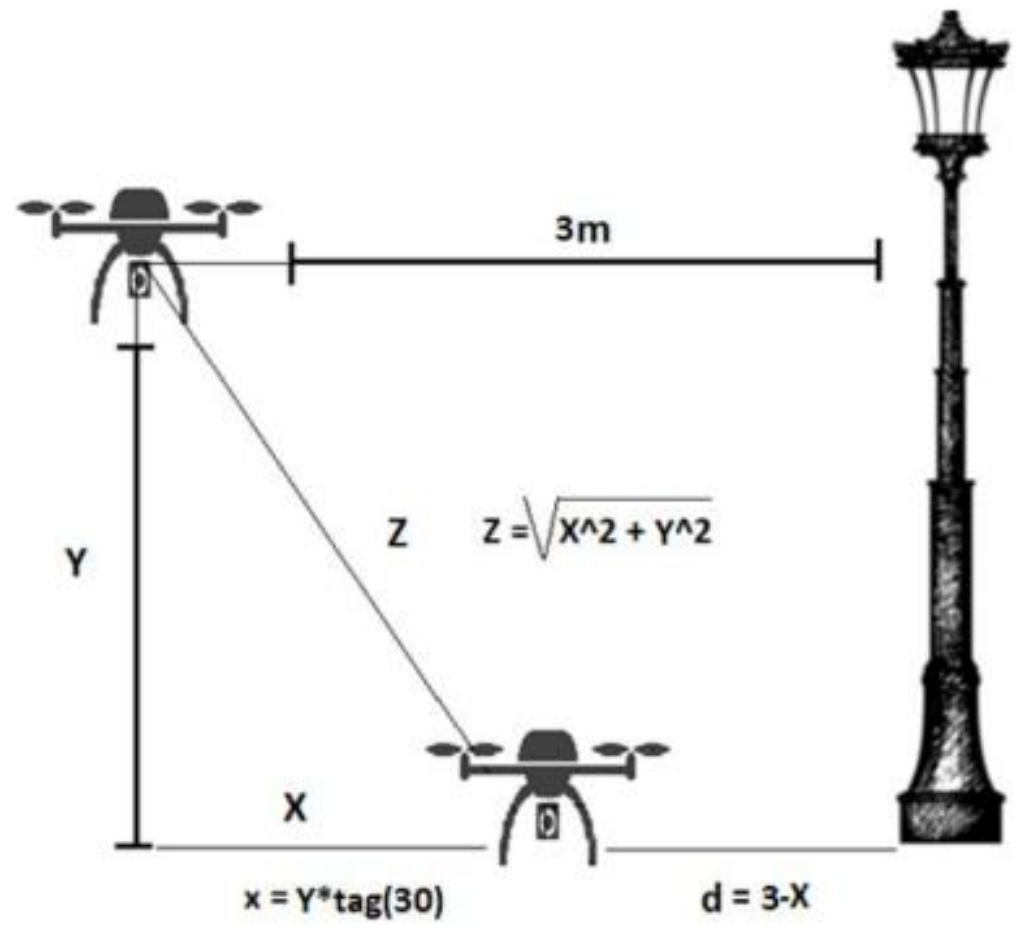

Elaborado por: Grupo de Investigación.

Con una calibración de descenso aproximada de 30 grados se pudo definir el valor de la pendiente y las distancias a las cuales el drone se encontrará al final del proceso. Por lo tanto, las estimaciones de las distancias se muestran en la tabla 4.

Tabla 4. Valores tolerables en los cuales el sistema basado en ultrasónico será eficiente

\begin{tabular}{cccccc}
\hline $\begin{array}{c}\text { Distancia de } \\
\text { detección } \\
\text { (metros) }\end{array}$ & $\begin{array}{c}\text { Altura del } \\
\text { drone } \mathbf{Y} \\
\text { (metros) }\end{array}$ & Distancia X & $\begin{array}{c}\text { Distancia de } \\
\text { descenso } \\
\text { recorrida Z } \\
\text { (metros) }\end{array}$ & $\begin{array}{c}\text { Distancia de } \\
\text { separación } \\
\mathbf{d} \text { (metros) }\end{array}$ & $\begin{array}{c}\text { Aceptación } \\
\text { con relación } \\
\text { a la altura }\end{array}$ \\
\hline 4 & 5 & 4,33 & 6,61 & $-0,33$ & NULA \\
4 & 4 & 3,46 & 5,29 & 0,54 & BAJA \\
4 & 3 & 2,60 & 3,97 & 1,40 & ALTA \\
4 & 2 & 1,73 & 2,65 & 2,27 & ALTA \\
4 & 1 & 0,87 & 1,32 & 3,13 & ALTA \\
\hline
\end{tabular}


En el momento de realizar las pruebas para la comparación de valores estimados vs. valores reales, se obtuvieron los siguientes resultados mostrados en la tabla 5.

Tabla 5. Valores estimados y reales de distancias de separación en el sistema anticolisiones.

\begin{tabular}{rrrrr}
\cline { 2 - 3 } & \multicolumn{2}{c}{$\begin{array}{c}\text { Distancia de separacion entre } \\
\text { el obstaculo }\end{array}$} & & \\
\hline $\begin{array}{c}\text { Altura } \\
\text { (metros) }\end{array}$ & $\begin{array}{c}\text { Posición } \\
\text { calculada } \\
\text { (metros) }\end{array}$ & $\begin{array}{c}\text { Posición real } \\
\text { (metros) }\end{array}$ & $\begin{array}{c}\text { Tiempo de aterrizaje } \\
\text { aproximado(segundos) }\end{array}$ & $\begin{array}{c}\text { Velocidad de } \\
\text { descenso } \\
\text { (metros/segundo) }\end{array}$ \\
\hline 3.5 & 0.98 & 1.10 & 6 & 0.81 \\
3 & 1.27 & 1.35 & 6 & 0.70 \\
2.5 & 1.55 & 1.62 & 5 & 0.67 \\
2 & 1.85 & 1.95 & 4 & 0.62 \\
1.5 & 2.13 & 2.20 & 3 & 0.71 \\
1 & 2.43 & 2.50 & 2 & 0.60 \\
0.5 & 2.71 & 2.79 & 1 & 0.67 \\
\hline
\end{tabular}

\section{Planeación de la misión.}

El tiempo máximo de vuelo es de 10 minutos en promedio, utilizando una batería de 4s, 3000 mAh, y una tasa de descarga de 30-40C. Este tiempo depende de factores como la velocidad de desplazamiento, la ruta a seguir y velocidad del viento, entre otras condiciones ambientales. Esto nos da como resultado un tiempo aproximado de 8 minutos de vuelo. La velocidad de vuelo es de $2 \mathrm{~m} / \mathrm{s}$, la captura de imágenes se lo realizo mediante la función de temporización en un lapso de 3 segundos, para tener un solapamiento mayor al 70\%. La altura de vuelo se determina en función del ancho del terreno, para que el ancho del terreno sea cubierto por una sola imagen. La finalidad es definir la trayectoria mas sencilla para el dron, es decir una línea recta obteniendo un menor numero de imágenes para procesar. Una vez configurada la ruta como se muestra en la figura 10, se procede a cargarla en el dron y a ejecutarla para la captura de las imágenes. 
Figura 10. Definición de la trayectoria a seguir.

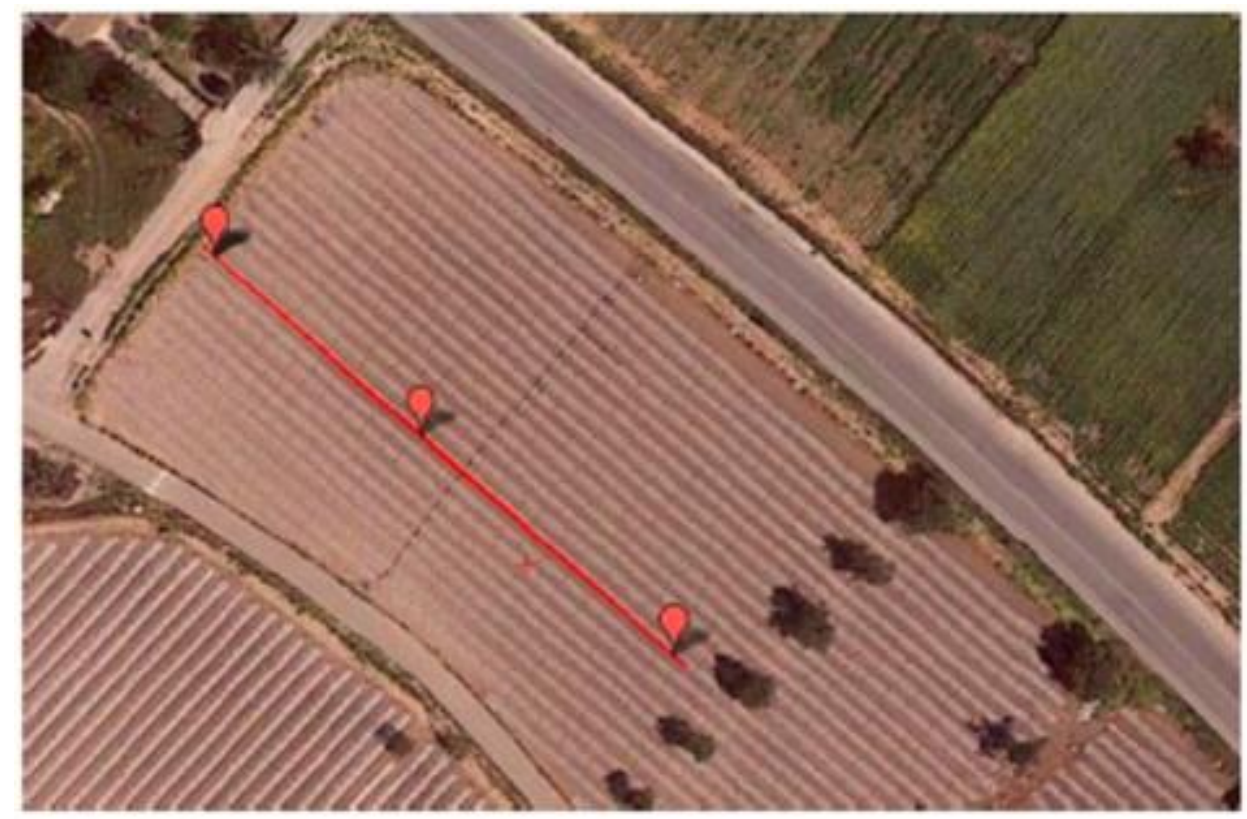

Elaborado por: Grupo de Investigación.

En la figura 11 se muestran los valores de distancia estimados por el GPS en Qground Control y los valores Reales medidos de manera manual.

Figura 11. Valores reales y estimados en las trayectorias.

\section{Comparación de Distancias}

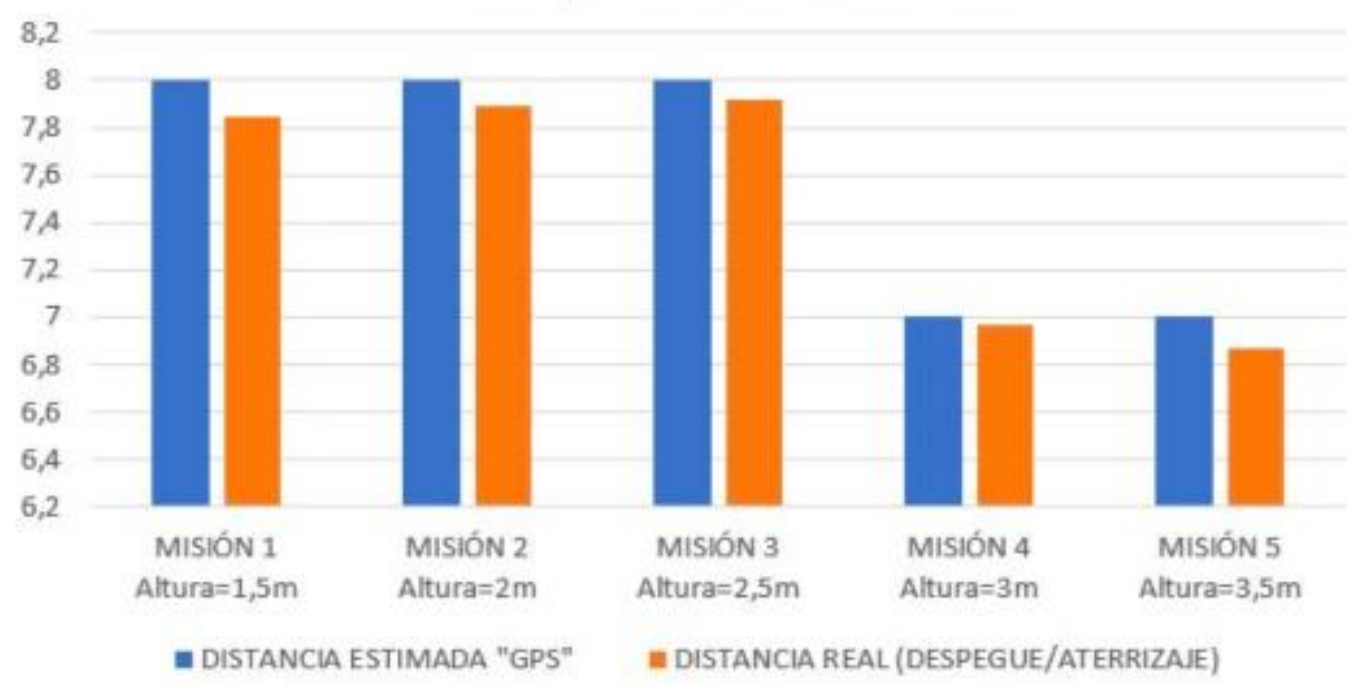

Elaborado por: Grupo de Investigación. 


\section{Conclusiones}

- Se ha investigado los principales conceptos sobre los vehículos aéreos no tripulados, logrando determinar que un vehículo tipo Quadcopter es la mejor opción para desarrollar el proyecto, debido a que podemos recorrer el terreno a menores velocidades logrando capturar imágenes mas estables y sin desenfoque, además, si se llega a presentar un obstáculo, el vehículo es capaz de efectuar un aterrizaje de emergencia.

- Se logro establecer una comunicación mediante una red wifi entre el dron y una computa- dora en tierra, usando el protocolo de comunicación MAVLink y el programa QGround Control, consiguiendo preestablecer la ruta que sigue el dron para capturar las imágenes y realizar un monitoreo y control de los parámetros de vuelo.

- Se implemento un sistema anticolisiones con la ayuda de un sensor ultrasónico y los módulos NRF24101 junto con Arduino, al enviar y recibir datos continuamente sobre la presencia de un posible obstáculo, switchgeando al acelerador del transmisor y reduciendo las revoluciones de los motores hasta desarmarlos.

- Mediante un algoritmo de segmentación y procesamiento de imágenes, se determino el numero de pixeles correspondientes a las plantas existentes en un terreno, y utilizando este valor, se logro determinar el área ocupada por el cultivo y el porcentaje de ocupación vegetal en relación con el área real del terreno.

- Se verifico que el dron implementado puede seguir una trayectoria preestablecida, además, que las imágenes capturadas presentan condiciones aceptables y que el valor resultante del procesamiento de imágenes, tienen valores proporcionales al aérea total de la zona donde se llevo a efecto el estudio

\section{Referencias Bibliográficas}

Devos, A., Ebeid, E., \& Manoonpong, P. (2018). Development of autonomous drones for adaptive obstacle avoidance in real world environments. In 
Proceedings - 21st Euromicro Conference on Digital System Design, DSD 2018. https://doi.org/10.1109/DSD.2018.00009

Jain, S. K., Ray, R. K., \& Bhavsar, A. (2015). Iterative solvers for image denoising with diffusion models: A comparative study. Computers and Mathematics with Applications. https://doi.org/10.1016/j.camwa.2015.04.009

Jian, C., Bin, Y., Hua, J., Lei, Z., \& Li, T. (2013). Interactive image segmentation by improved maximal similarity based region merging. In ICMIPE 2013 Proceedings of 2013 IEEE International Conference on Medical Imaging Physics and Engineering. https://doi.org/10.1109/ICMIPE.2013.6864551

Moribe, T., Okada, H., Kobayashl, K., \& Katayama, M. (2018). Combination of a wireless sensor network and drone using infrared thermometers for smart agriculture. In CCNC 2018 - 2018 15th IEEE Annual Consumer Communications and Networking Conference. https://doi.org/10.1109/CCNC.2018.8319300

Morita, M., Kinjo, H., \& Sato, S. (2018). Autonomous flight drone for infrastructure (transmission line) inspection (3). In ICIIBMS 2017 - 2nd International Conference on Intelligent Informatics and Biomedical Sciences. https://doi.org/10.1109/ICIIBMS.2017.8279692

Murugan, D., Garg, A., Ahmed, T., \& Singh, D. (2018). Fusion of drone and satellite data for precision agriculture monitoring. In 11th International Conference on Industrial and Information Systems, ICIIS 2016 - Conference Proceedings. https://doi.org/10.1109/ICIINFS.2016.8263068

Rivaz, H., Karimaghaloo, Z., \& Collins, D. L. (2014). Self-similarity weighted mutual information: A new nonrigid image registration metric. Medical Image Analysis. https://doi.org/10.1016/j.media.2013.12.003

Tripicchio, P., Satler, M., Dabisias, G., Ruffaldi, E., \& Avizzano, C. A. (2015).

Towards Smart Farming and Sustainable Agriculture with Drones. In Proceedings - 2015 International Conference on Intelligent Environments, IE 
2015. https://doi.org/10.1109/IE.2015.29

Wang, X., Yadav, V., \& Balakrishnan, S. N. (2007). Cooperative UAV formation flying with obstacle/collision avoidance. IEEE Transactions on Control

Systems Technology. https://doi.org/10.1109/TCST.2007.899191

Yallappa, D., Veerangouda, M., Maski, D., Palled, V., \& Bheemanna, M. (2017).

Development and evaluation of drone mounted sprayer for pesticide applications to crops. In GHTC 2017 - IEEE Global Humanitarian Technology Conference, Proceedings. https://doi.org/10.1109/GHTC.2017.8239330

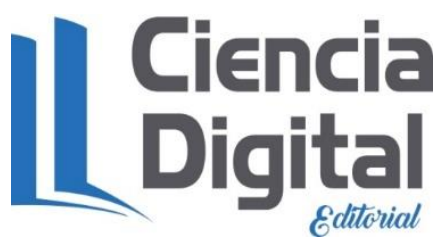




\section{PARA CITAR EL ARTÍCULO INDEXADO.}

Santacruz Sulca, F., Cabrera Aguayo, F., Olmedo Carrillo, W., \& Tacuri Auquilla, J. (2019). Implementación de un Dron Anticolisiones Capaz de Seguir una Trayectoria Preestablecida para la Elaboración de un Mapa de la Tasa de Ocupación Vegetal en una Zona. Ciencia Digital, 3(3.3), 356374. https://doi.org/10.33262/cienciadigital.v3i3.3.827

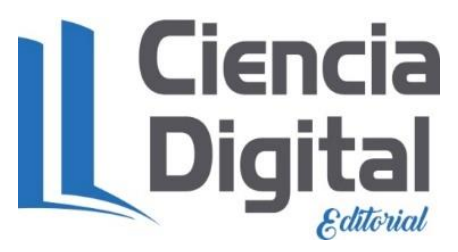

El artículo que se publica es de exclusiva responsabilidad de los autores y no necesariamente reflejan el pensamiento de la Revista Ciencia Digital.

El artículo queda en propiedad de la revista y, por tanto, su publicación parcial y/o total en otro medio tiene que ser autorizado por el director de la Revista Ciencia Digital.
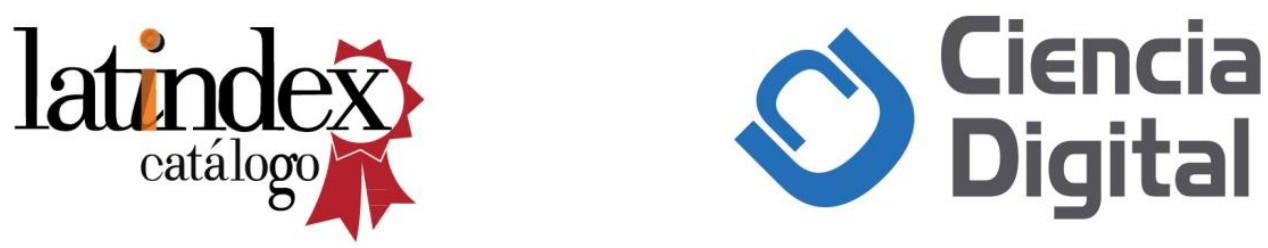